\title{
Prognostic value of regional lymph node involvement in patients with metastatic colorectal cancer: palliative versus curative resection
}

Ya-Ting Kuo ${ }^{1}$, Wen-Sy Tsai ${ }^{1}$, Hsin-Yuan Hung ${ }^{1,2}$, Pao-Shiu Hsieh ${ }^{1}$, Sum-Fu Chiang ${ }^{1}$, Cheng-Chou Lai ${ }^{1}$, Yih-Jong Chern', Yu-Jen Hsu ${ }^{1}$ and Jeng-Fu You ${ }^{1 *}$

\begin{abstract}
Background: Approximately $20 \%$ of patients with colorectal cancer are initially diagnosed with stage IV disease. This study aims to examine the role of regional lymph node (LN) status in metastatic colorectal cancer (mCRC) with respect to clinicopathologic features and survival outcomes.

Methods: We investigated 1147 patients diagnosed with $\mathrm{mCRC}$ and had undergone surgical resection of the primary CRC. A total of 167 patients were placed in the $L N$-negative $(L N-)$ group and another 980 in the LNpositive $(\mathrm{LN}+)$ group.

Results: $L N+$ patients exhibited a significantly higher rate of T4 tumors $(p=0.008)$, poorly differentiated adenocarcinoma ( $p<0.001)$, lymphovascular invasion $(p<0.001)$, and perineural invasion $(p<0.001)$ than those in the $L N$ - group. LN- patients had a significantly higher rate of lung metastasis $(p<0.001)$, whereas the rate of peritoneal seeding $(p<0.001)$ and systemic node metastasis $(p<0.001)$ was both significantly higher in the LN+ group. The 5 -year overall survival (OS) in the LN+ group was significantly poorer than that in the LN- group (LNvs. $L N+23.2 \%$ vs. $18.1 \% ; p=0.040$ ). In patients with curative resection, the 5 -year OS rate has no significant difference between the two groups ( $L N-$ vs. $L N+19.5 \%$ vs. $24.3 \% ; p=0.890$ ).

Conclusions: Metastatic CRC patients with $L N+$ who underwent primary tumor resection may present with more high-risk pathological features, more peritoneal seeding, and systemic node metastasis, but less lung metastasis than $\mathrm{LN}$ - patients. LN+ patients had poorer long-term outcomes compared with that in $L N-$ patients. Nevertheless, with curative resection, $\mathrm{LN}+$ patients could have similar survival outcomes as $L N-$ patients.
\end{abstract}

\section{Introduction}

Approximately $20 \%$ of newly diagnosed colorectal cancer patients present with synchronous distant metastasis, the majority of whom are only eligible for treatment with palliative intent, and the prognosis in these patients is

\footnotetext{
* Correspondence: jenodyssey@gmail.com

'Division of Colon and Rectal Surgery, Department of Surgery, Chang Gung Memorial Hospital at Linkou, Chang Gung University College of Medicine, No. 5, Fuxing Street, Guishan District, Taoyuan City, Taiwan

Full list of author information is available at the end of the article
}

usually poor [1-5]. In patients with metastatic colorectal cancer (mCRC), curative or palliative operation is sometimes performed and has favorable prognostic impact, especially when the primary tumor and metastatic region can be resected [6-11]. Advances in systemic chemotherapy and target therapy have provided therapeutic options and led to a remarkable increase in OS (from less than 1 year to 30 months or longer) [12-18]. The 5year OS rate is approximately $20 \%$ in patients treated

C C The Author(s). 2021 Open Access This article is licensed under a Creative Commons Attribution 4.0 International License, which permits use, sharing, adaptation, distribution and reproduction in any medium or format, as long as you give appropriate credit to the original author(s) and the source, provide a link to the Creative Commons licence, and indicate if changes were made. The images or other third party material in this article are included in the article's Creative Commons licence, unless indicated otherwise in a credit line to the material. If material is not included in the article's Creative Commons licence and your intended use is not permitted by statutory regulation or exceeds the permitted use, you will need to obtain permission directly from the copyright holder. To view a copy of this licence, visit http://creativecommons.org/licenses/by/4.0/ The Creative Commons Public Domain Dedication waiver (http://creativecommons.org/publicdomain/zero/1.0/) applies to the data made available in this article, unless otherwise stated in a credit line to the data. 
with chemotherapy alone $[19,20]$. In patients with liver metastases, the 5-year OS rate after curative resection of both primary and metastatic lesions varies from 25 to $58 \%$, whereas in those with lung metastases, it varies from 25 to $52 \%$ [21, 22].

Considering metastasis can be fatal, its development is a concern for patients and clinicians. Clinical data represent an essential basis for postoperative clinical surveillance in mCRC patients. However, the mechanisms and routes of metastasis in CRC are poorly understood, and the prognostic factors can only be surmised from demographic data and epidemiologic reports. According to previous reports, around $18 \%$ of patients with mCRC did not present regional LN involvement [23, 24]. A newly developed mouse model of CRC has demonstrated that liver metastases can develop without prior LN involvement [25].

The proposed metastatic routes are hematogenous, lymphatic, and transcoelomic/transperitoneal spread, and the common CRC metastatic sites are the liver, lung, peritoneum, and systemic LNs [26]. Since venous drainage of the intestinal tract occurs through the portal system, the first site of hematogenous spread is usually the liver, followed by the lungs, bones, brain, and other sites. However, the distal rectum may initially metastasize to the lungs because drainage return travels from the inferior rectal vein to the inferior vena cava (IVC) rather than the portal venous system. Tumor cells in some patients are directly transferred to the lungs through the lymphatic system, whereas others may have peritoneal seeding through transcoelomic/transperitoneal spread [26-28].

Metastatic patterns usually differ according to histologic type, histologic grade, and tumor location. According to Riihimäki et al., rectal cancer more frequently metastasized into the thoracic organs and nervous system than into the peritoneum, and more peritoneum seeding occurred in mucinous and signet ring adenocarcinoma. Survival in CRC patients with solitary metastases ranged from 5 to 19 months, depending on the $\mathrm{T}$ and $\mathrm{N}$ stage [29].

In this study, we examined the role of regional LN status in patients with mCRC concerning clinicopathologic features, metastatic sites, and survival outcomes. This information using a real-world dataset may help elucidate the association of regional LN and distant metastatic organs in patients with $\mathrm{mCRC}$.

\section{Methods}

\section{Patients and variables}

Detailed data for patients who had been diagnosed with $\mathrm{mCRC}$ who had undergone primary colorectal tumor resection with or without metastasectomy between January 2003 and December 2015 were retrospectively retrieved from routinely collected data in the Colorectal Section Tumor Registry at Chang-Gung Memorial Hospital $(\mathrm{CGMH})$. The hospital's institutional review board approved this study. Clinical staging was determined mainly through computed tomography, whereas some peritoneal seeding tumors were confirmed during operation. Exclusion criteria included distant metastases of non-colorectal origin, patients receiving local excision or bypass surgery with no primary tumor resection, patients receiving neoadjuvant therapy, and patients undergoing emergency surgery. Patients with mCRC were then divided into two groups depending on whether regional LN metastases were present. Following primary tumor resection, patients whose pathologic reports indicated no regional LN metastasis were classified as the lymph node-negative ( $\mathrm{LN}-$ ) group, whereas those with any positive regional LN were classified as the lymph nodepositive $(\mathrm{LN}+)$ group.

The available medical records included data on sex, age, body mass index (BMI), family cancer history (including familial adenomatous polyposis and hereditary nonpolyposis colorectal cancer), and underlying medical conditions (e.g., hypertension, cardiac disease, and diabetes mellitus). Preoperative blood tests were also recorded, including hemoglobin, albumin, creatinine, carcinoembryonic antigen (CEA), and total bilirubin levels. Tumor-related clinicopathologic variables included tumor location, diameter and invasion depth, number of positive LNs, circumferential involvement, curative resection, histologic type, histologic grade, desmoplastic reaction, tumor necrosis, lymphovascular invasion (LVI), and perineural invasion (PNI).

Treatment strategies, including postoperative palliative therapy (target therapy, chemotherapy, radiation, chemoradiation), were recorded. The selection of regimen for postoperative palliative therapy was independent to regional lymph node status. The choice of surgical removal for primary CRC was influenced by whether patients presented with symptoms such as tumor bleeding or obstruction, the potential for curative resection of the primary tumor and distant metastatic sites, and the individual physician's judgment. Different physicians in the colorectal section of the Chang-Gung Memorial Hospital (CGMH) adopted similar treatment strategies, and all patients were assessed at weekly multidisciplinary team meetings to clarify the diagnosis and metastatic sites according to their clinical information and develop treatment plans. The presence of distant metastasis was documented, with metastatic site subgroups comprising the liver, lungs, peritoneal carcinomatosis, systemic node, ovary, bone, brain, and others (including rare locations, such as the bladder, uterus, pelvic wall, adrenal gland, skin, and kidney). 
Morbidity and mortality were classified as postoperative complications. Morbidity was defined as woundrelated (wound infection or dehiscence), pulmonary (atelectasis, pneumonia), cardiovascular (myocardial infarction, stroke, embolism), urinary (urinary tract infection, neurogenic bladder), gastrointestinal (obstruction, ileum, bleeding), anastomosis-related (leakage, stenosis), and other complications occurring within 30 days after surgery. Postoperative mortality was defined as death occurring during the hospital stay or within 30 days after surgery. Prognosis was evaluated based on OS, with the OS interval defined as the duration between the date of initial surgery and the date of death or the latest followup.

\section{Statistical analysis}

All analyses were performed using IBM SPSS Statistics, version 24.0 (IBM Corp., Armonk, NY, USA). Clinicopathologic characteristics were compared using the chisquared test for categorical variables, Student's $t$-test for continuous data with normal distribution, and MannWhitney $U$ test for continuous data against normal distribution. OS was calculated through univariate analyses using the Kaplan-Meier method. Differences were estimated using the log-rank test. Statistical significance was set at $\mathrm{p}<0.05$.

\section{Results}

We enrolled and analyzed 1147 patients, divided into the LN- group (167 patients) and LN+ group (980 patients) (Fig. 1). The mean age of these patients was 61.7 years, and their median follow-up time was 23.9 months.

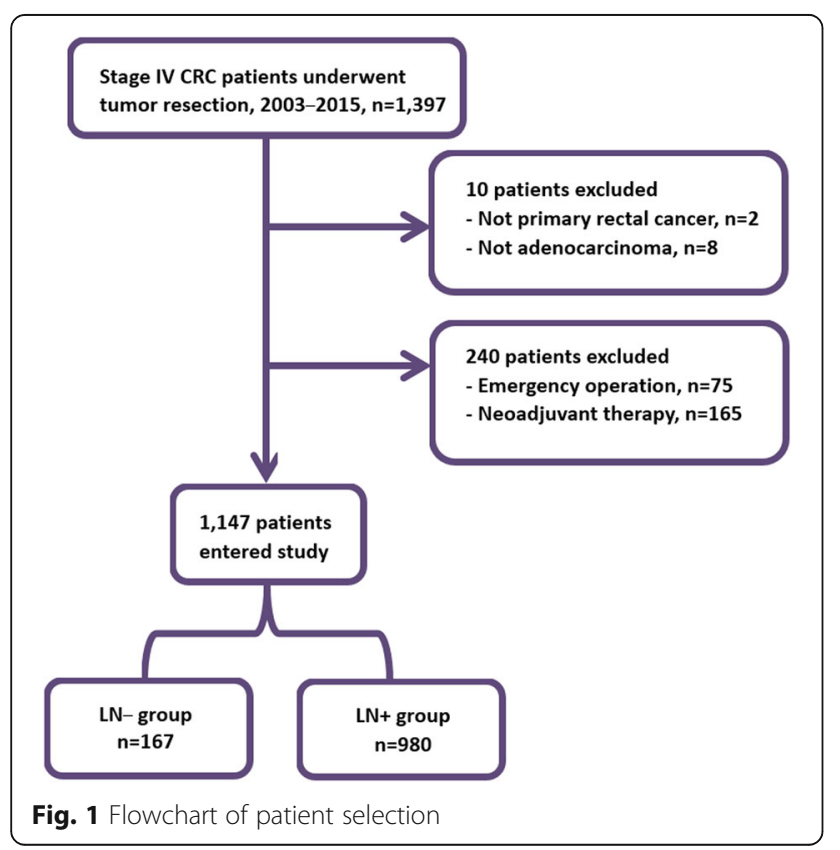

Demographic data are listed in Table 1. No statistical differences were found between the two groups for sex, age, BMI, family cancer history, and presence of comorbidities, including hypertension, cardiac disease, and diabetes mellitus. No statistical differences were found between the two groups in preoperative laboratory data, including CEA, hemoglobin, albumin, creatinine, and total bilirubin levels.

The treatment data are listed in Table 2. No significant difference was found between the two groups in terms of postoperative palliative therapy $(\mathrm{p}=0.506)$, postoperative morbidity $(\mathrm{p}=0.832)$, postoperative mortality $(\mathrm{p}=$

Table 1 Demographics and laboratory variables

\begin{tabular}{|c|c|c|c|}
\hline & $\begin{array}{l}\text { LN- group } \\
\mathrm{n}=167(\%)\end{array}$ & $\begin{array}{l}\text { LN+ group } \\
n=980(\%)\end{array}$ & $\bar{p}$ value \\
\hline \multicolumn{4}{|l|}{ Sex } \\
\hline Male & $93(55.7)$ & $556(56.7)$ & 0.801 \\
\hline Female & $74(44.3)$ & $424(43.3)$ & \\
\hline Age (year) & $62.0 \pm 15.1$ & $61.7 \pm 14.2$ & 0.776 \\
\hline Age $<50$ & $35(21)$ & $192(19.6)$ & 0.682 \\
\hline Age $\geq 50$ & $132(79)$ & $788(80.4)$ & \\
\hline$B M l^{\mathrm{a}}$ & $23.4 \pm 3.9$ & $23.5 \pm 3.6$ & 0.738 \\
\hline$<25$ & $110(66.7)$ & $674(69.6)$ & 0.458 \\
\hline$\geq 25$ & $55(33.3)$ & $295(30.4)$ & \\
\hline \multicolumn{4}{|l|}{ Family cancer history } \\
\hline Yes & $58(34.9)$ & $387(40.2)$ & 0.198 \\
\hline No & $108(65.1)$ & $575(59.8)$ & \\
\hline \multicolumn{4}{|l|}{ Medical illness } \\
\hline Hypertension & $52(31.1)$ & $308(31.4)$ & 0.940 \\
\hline Cardiac disease & $10(6)$ & $73(7.4)$ & 0.501 \\
\hline Diabetes mellitus & $26(15.6)$ & $149(15.2)$ & 0.904 \\
\hline \multicolumn{4}{|l|}{$\mathrm{CEA}^{\mathrm{a}}(\mathrm{ng} / \mathrm{mL})$} \\
\hline$C E A<5$ & $48(29.1)$ & $263(27.6)$ & 0.687 \\
\hline$C E A \geq 5$ & $117(70.9)$ & $691(72.4)$ & \\
\hline Hemoglobin (g/dL) & $11.6 \pm 2.4$ & $11.6 \pm 2.5$ & 0.879 \\
\hline$\geq 10$ & $128(76.6)$ & $733(74.8)$ & 0.609 \\
\hline$<10$ & $39(23.4)$ & $247(25.2)$ & \\
\hline Albumin $^{\mathrm{a}}(\mathrm{g} / \mathrm{dL})$ & $3.9 \pm 0.6$ & $3.9 \pm 0.6$ & 0.793 \\
\hline Albumin $<3.5$ & $29(18)$ & $161(17.1)$ & 0.775 \\
\hline Albumin $\geq 3.5$ & $132(82)$ & $781(82.9)$ & \\
\hline \multicolumn{4}{|l|}{ Creatinine $^{\mathrm{a}}(\mathrm{mg} / \mathrm{dL})$} \\
\hline Normal & $138(83.6)$ & $793(82.9)$ & 0.807 \\
\hline Abnormal & $27(16.4)$ & $164(17.1)$ & \\
\hline \multicolumn{4}{|c|}{ Total bilirubin ${ }^{\mathrm{a}}(\mathrm{mg} / \mathrm{dL})$} \\
\hline Normal & $152(98.7)$ & $853(96.4)$ & 0.136 \\
\hline Abnormal & $2(1.3 \%)$ & $32(3.6)$ & \\
\hline
\end{tabular}

CEA carcinoembryonic antigen

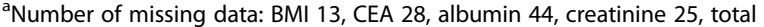
bilirubin 108 
Table 2 Treatment modality and operative outcomes

\begin{tabular}{|c|c|c|c|}
\hline & $\begin{array}{l}\text { LN- group } \\
n=167(\%)\end{array}$ & $\begin{array}{l}\text { LN+ group } \\
\mathrm{n}=980(\%)\end{array}$ & $p$ value \\
\hline \multicolumn{4}{|c|}{ Postoperative palliative therapy } \\
\hline Yes & $135(80.8)$ & $814(83.1)$ & 0.506 \\
\hline No & $32(19.2)$ & $166(16.9)$ & \\
\hline \multicolumn{4}{|l|}{ Morbidity } \\
\hline Yes & $25(15)$ & $153(15.6)$ & 0.832 \\
\hline No & $142(85)$ & $827(84.4)$ & \\
\hline \multicolumn{4}{|l|}{ Mortality } \\
\hline Yes & $3(1.8)$ & $13(1.3)$ & 0.632 \\
\hline No & $164(98.2)$ & $967(98.7)$ & \\
\hline Days of admission & $14[11-19]^{*}$ & $13[11-17]^{*}$ & 0.145 \\
\hline
\end{tabular}

${ }^{*}$ Median [25 percentile-75 percentile]

$0.632)$, and length of hospital stay ( $\mathrm{p}=0.145)$. A total of 178 patients $(15.5 \%)$ had postoperative morbidities (25 in the LN- group, 153 in the $\mathrm{LN}+$ group), and postoperative mortality occurred in 16 patients $(1.4 \% ; 3$ in the $\mathrm{LN}$ - group, 13 in the $\mathrm{LN}+$ group).

The pathological characteristics are displayed in Table 3. The tumor location distribution was similar in both groups $(\mathrm{p}=0.066)$. No statistical differences between the two groups were found for circumferential tumor involvement $(\mathrm{p}=0.631)$ and tumor size larger than $5 \mathrm{~cm}(\mathrm{p}=0.313)$. Patients in the $\mathrm{LN}+$ group had more T4 tumors than those in the LN- group (percentage of patients with T4 tumors $48.2 \%$ vs. $37.1 \%$, respectively; $p=0.008)$. Similarly, no statistical differences were found in the local tumor clearance rate of the two groups. The median positive $\mathrm{LN}$ count in the $\mathrm{LN}+$ group was 6 (range, 1-84). Moreover, no statistical differences between the groups were found for histology type, desmoplastic tumor reaction, and tumor necrosis. In primary tumor histology grade, the $\mathrm{LN}+$ group exhibited a higher rate of poorly differentiated adenocarcinoma than that in the $\mathrm{LN}$ - group ( $\mathrm{LN}-$ vs. $\mathrm{LN}+7.2 \%$ vs. $19.2 \%$; $\mathrm{p}<$ $0.001)$. LVI and PNI both occurred more frequently in the $\mathrm{LN}+$ group than that in the $\mathrm{LN}$ - group (LVI rate in $\mathrm{LN}-$ vs. $\mathrm{LN}+, 23.4 \%$ vs. $77.4 \%, \mathrm{p}<0.001$; PNI rate in $\mathrm{LN}$ - vs. $\mathrm{LN}+, 34.7 \%$ vs. $59.7 \%$, p $<0.001$ ).

An analysis of the metastatic characteristics is presented in Table 4. The rate of liver metastasis was similar in both groups $(p=0.114)$. Patients in the LNgroup had a higher lung metastasis rate than those in the $\mathrm{LN}+$ group $(25.7 \%$ vs. $14.6 \%$, respectively; $\mathrm{p}<0.001)$. The frequency of peritoneal seeding and systemic node metastasis was higher in the $\mathrm{LN}+$ group (peritoneal seeding in $\mathrm{LN}-$ vs. $\mathrm{LN}+, 17.4 \%$ vs. $32.4 \%$, p < 0.001 ; systemic node metastasis in $\mathrm{LN}-$ vs. $\mathrm{LN}+, 6 \%$ vs. $17 \%$, p < $0.001)$. No statistical differences between the two groups were found in terms of the ovary, bone, brain, and other metastasis sites, which included the bladder, uterus, pelvic wall, adrenal gland, skin, and kidney.

The 5 -year OS rate was $18.8 \%$, with a median survival of 24 months for all patients analyzed. In the LNgroup, the 5-year OS rate was $23.2 \%$, with a median survival of 28 months. In the $\mathrm{LN}+$ group, the 5-year OS rate was $18.1 \%$, with a median survival of 23.7 months. Patients in the LN+ group had a lower 5-year OS rate than those in the LN- group (LN- vs. LN+ $23.2 \%$ vs. $18.1 \%$; $\mathrm{p}=0.040$ ) (Fig. 2). Survival analysis of patients with curative (R0) and non-curative (non-R0) resection was performed ( $\mathrm{n}=1147,342$ patients in the $\mathrm{R} 0$ group and 805 patients in the non-R0 group). In the R0 resection group, the 5 -year OS rate was $23.4 \%$, with a median survival of 27.1 months, whereas in the non-R0 resection group, the 5-year OS rate was $16.7 \%$, with a median survival of 23.1 months. Patients in the R0 resection group had a higher 5-year OS rate than those in the non-R0 resection group (R0 vs. non-R0 $23.4 \%$ vs. $16.7 \%$; $\mathrm{p}=0.013$ ) (Fig. 2).

Survival analysis of patients with curative (R0) resection of both primary and metastatic lesions was performed ( $\mathrm{n}=342,59$ patients in the $\mathrm{LN}$ - group and 283 patients in the $\mathrm{LN}+$ group). The 5-year OS rate was $23.5 \%$, with a median survival of 27.1 months for all R0 resection patients analyzed. In the LN- group, the 5year OS rate was $19.5 \%$, with a median survival of 29.5 months, whereas in the $\mathrm{LN}+$ group, the 5-year OS rate was $24.3 \%$, with a median survival of 27 months. The 5year OS rate was not significantly different between the two groups (LN- vs. $\mathrm{LN}+19.5 \%$ vs. $24.3 \%$; p $=0.890$ ) (Fig. 2).

Survival analysis of patients with non-curative (nonR0) resection was performed ( $\mathrm{n}=805,108$ patients in the LN- group and 697 patients in the $\mathrm{LN}+$ group). The 5 -year OS rate was $16.7 \%$, with a median survival of 23 months for all non-R0 resection patients analyzed. In the LN- group, the 5 -year OS rate was $26 \%$, with a median survival of 28 months, whereas in the LN+ group, the 5 -year OS rate was $15.4 \%$, with a median survival of 22.4 months. Non-R0 resection patients in the $\mathrm{LN}+$ group had a lower 5-year OS rate than those in the LNgroup (LN- vs. LN+ 26\% vs. 15.4\%; p = 0.013) (Fig. 2).

\section{Discussion}

The main aim of this study was to examine the role of regional LNs resected during surgery in mCRC patients. The LN- group had 167 patients, while the LN+ group had 980 patients. The two groups had similar demographic data and preoperative laboratory variables. No significant difference between the two groups was found for postoperative morbidity and mortality rates. Regarding histopathologic features of primary tumor, the LN+ group exhibited a higher rate of $\mathrm{T} 4$ tumors and poorly 
Table 3 Tumor characteristics

\begin{tabular}{|c|c|c|c|}
\hline & $\begin{array}{l}\text { LN- group } \\
n=167(\%)\end{array}$ & $\begin{array}{l}\text { LN+ group } \\
\mathrm{n}=980(\%)\end{array}$ & $\mathrm{p}$ value \\
\hline \multicolumn{4}{|l|}{ Tumor location } \\
\hline Right side colon & $34(20.4)$ & $284(29)$ & \multirow[t]{3}{*}{0.066} \\
\hline Left side colon & $71(42.5)$ & $360(36.7)$ & \\
\hline Rectum & $62(37.1)$ & $336(34.3)$ & \\
\hline \multicolumn{4}{|l|}{ Circumferential involvement } \\
\hline Yes & $122(73.1)$ & $734(74.9)$ & \multirow[t]{2}{*}{0.631} \\
\hline No & $45(26.9)$ & $246(25.1)$ & \\
\hline \multicolumn{4}{|l|}{ Associated polyps } \\
\hline Yes & $61(36.5)$ & $394(40.2)$ & \multirow[t]{2}{*}{0.369} \\
\hline No & $106(63.5)$ & $586(59.8)$ & \\
\hline \multicolumn{4}{|l|}{ Tumor diameter $(\mathrm{cm})$} \\
\hline$<5 \mathrm{~cm}$ & $82(49.1)$ & $437(44.6)$ & \multirow[t]{2}{*}{0.313} \\
\hline$\geq 5 \mathrm{~cm}$ & $85(50.9)$ & $543(55.4)$ & \\
\hline \multicolumn{4}{|l|}{ Depth of tumor invasion } \\
\hline T4 & $62(37.1)$ & $472(48.2)$ & \multirow[t]{2}{*}{0.008} \\
\hline Non-T4 & $105(62.9)$ & $508(51.8)$ & \\
\hline Examined LN number & $25[16-39]^{*}$ & 28 [19-39]* & 0.038 \\
\hline Total positive LN number & $0[0-0]^{*}$ & $6[3-11]^{*}$ & $<0.001$ \\
\hline \multicolumn{4}{|l|}{ Local tumor clearance } \\
\hline RO & $59(35.3)$ & $283(28.9)$ & \multirow[t]{2}{*}{0.092} \\
\hline Non-RO & $108(64.7)$ & $697(71.1)$ & \\
\hline \multicolumn{4}{|l|}{ Histologic type } \\
\hline Adenocarcinoma & $155(92.8)$ & $873(89.1)$ & \multirow[t]{3}{*}{0.121} \\
\hline Signet ring cell adenocarcinoma & $1(0.6)$ & $34(3.5)$ & \\
\hline Mucinous adenocarcinoma & $11(6.6)$ & $73(7.4 \%)$ & \\
\hline \multicolumn{4}{|l|}{ Histologic grade ${ }^{a}$} \\
\hline Well or moderately differentiated & $155(92.8)$ & $789(80.8)$ & \multirow[t]{2}{*}{$<0.001$} \\
\hline Poorly differentiated & $12(7.2)$ & $188(19.2)$ & \\
\hline \multicolumn{4}{|l|}{ Desmoplastic reaction ${ }^{a}$} \\
\hline Mild & $41(24.6)$ & $209(21.3)$ & \multirow[t]{3}{*}{0.331} \\
\hline Moderate & $106(63.5)$ & $613(61.6)$ & \\
\hline Marked & $20(12)$ & $157(16)$ & \\
\hline \multicolumn{4}{|l|}{ Tumor necrosis ${ }^{a}$} \\
\hline Mild & $72(49.7)$ & $414(47)$ & \multirow[t]{3}{*}{0.824} \\
\hline Moderate & $53(36.6)$ & $344(39.1)$ & \\
\hline Marked & $20(13.8)$ & $122(13.9)$ & \\
\hline \multicolumn{4}{|l|}{ Lymphovascular invasion $^{a}$} \\
\hline Yes & $39(23.4)$ & $755(77.4)$ & \multirow[t]{2}{*}{$<0.001$} \\
\hline No & $128(76.6)$ & $221(22.6)$ & \\
\hline \multicolumn{4}{|l|}{ Perineural invasion ${ }^{a}$} \\
\hline Yes & $58(34.7)$ & $581(59.7)$ & \multirow[t]{2}{*}{$<0.001$} \\
\hline No & $109(65.3)$ & $393(40.3)$ & \\
\hline
\end{tabular}

*Median [25 percentile-75 percentile]

a Number of missing data: histologic grade 3, desmoplastic reaction 1, tumor necrosis 122, lymphovascular invasion 4, perineural invasion 6 
Table 4 Metastatic sites

\begin{tabular}{llll}
\hline & $\begin{array}{l}\text { LN- group } \\
\mathbf{n}=\mathbf{1 6 7}(\%)\end{array}$ & $\begin{array}{l}\text { LN+ group } \\
\mathbf{n = 9 8 0}(\%)\end{array}$ & p value \\
\hline Liver & $106(63.5)$ & $558(56.9)$ & 0.114 \\
Lung & $43(25.7)$ & $143(14.6)$ & $<0.001$ \\
Peritoneal seeding & $29(17.4)$ & $318(32.4)$ & $<0.001$ \\
Systemic node & $10(6)$ & $167(17)$ & $<0.001$ \\
Ovary & $6(3.6)$ & $53(5.4)$ & 0.326 \\
Bone & $2(1.2)$ & $7(0.7)$ & 0.513 \\
Brain & $0(0)$ & $2(0.2)$ & 0.559 \\
Other metastatic sites & $6(3.6)$ & $44(4.5)$ & 0.600 \\
\hline
\end{tabular}

${ }^{\mathrm{a}}$ Other metastatic sites include the bladder, uterus, pelvic wall, adrenal gland, skin, and kidney

differentiated adenocarcinoma. The presence of both LVI and PNI was higher in the LN+ group than that in the LN- group. Patients in the LN- group had a higher frequency of lung metastasis, whereas peritoneal seeding and systemic node metastasis occurred more frequently in the $\mathrm{LN}+$ group. The 5-year OS rate of the $\mathrm{LN}+$ group was significantly poorer than that of the $\mathrm{LN}$ - group.
In this study, the LN+ group exhibited a higher rate of poorly differentiated adenocarcinoma as well as a higher rate of LVI and PNI than that in the LN- group. The 5year OS rate in the LN+ group was significantly poorer than that in the LN- group (LN- vs. LN+ $23.2 \%$ vs. $18.1 \% ; \mathrm{p}=0.040$ ). Our previous research suggested that poor differentiation and LVI were independent risk factors predicting LN metastasis in pT1-2 rectal carcinoma [30]. One other study also indicated that LVI and PNI were poor prognostic factors in patients with stages II and III CRC [31]. One Korean study analyzed patients with $\mathrm{T} 1$ or $\mathrm{T} 2 \mathrm{CRCs}$ who underwent radical surgery with regional lymphadenectomy, revealing that LN status was the only significant independent prognostic factor for both OS $(\mathrm{p}=0.025)$ and disease-free survival ( $\mathrm{p}$ $=0.040)$; moreover, the presence of LVI $(\mathrm{p}<0.001)$ or PNI ( $\mathrm{p}=0.004)$ was an independent predictor of LN metastasis [32]. Liebig et al. also reported that PNI could serve as an independent prognostic factor in CRC patients [33]. As for mCRC, the present study's findings imply that patients in the $\mathrm{LN}+$ group had more characteristics related to poorer prognosis (poor differentiation, a.

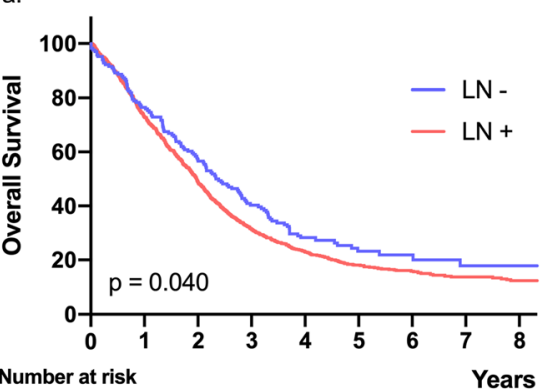

$\begin{array}{llllllllll}\text { LN- } & 167 & 127 & 95 & 66 & 36 & 21 & 12 & 8 & 5\end{array}$

$\begin{array}{llllllllll}\text { LN+ } & 980 & 713 & 477 & 303 & 177 & 105 & 69 & 41 & 34\end{array}$

c.

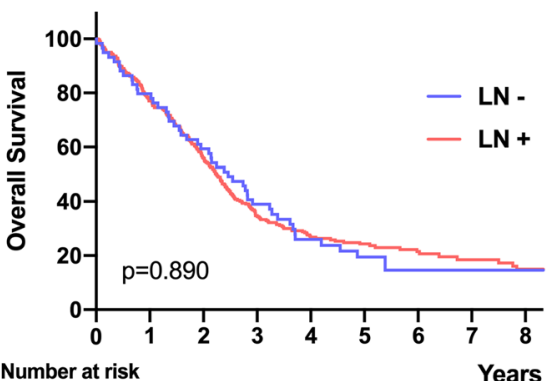

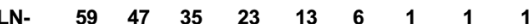

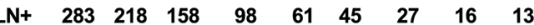

b.

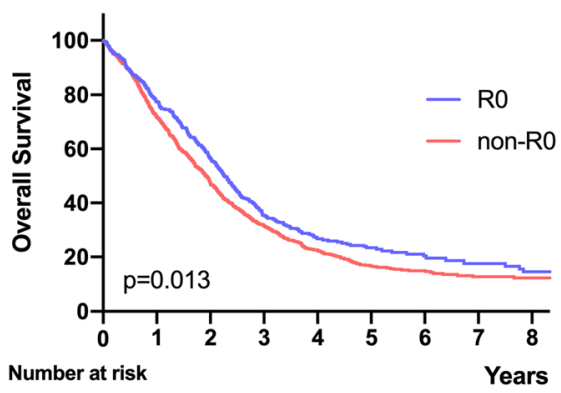

$\begin{array}{llllllllll}\text { Ro } & 342 & 265 & 193 & 121 & 74 & 51 & 28 & 17 & 14\end{array}$

Non-R0 $805 \quad 575 \quad 379 \quad 248 \quad 139 \quad 75 \quad 53 \quad 32 \quad 25$

d.

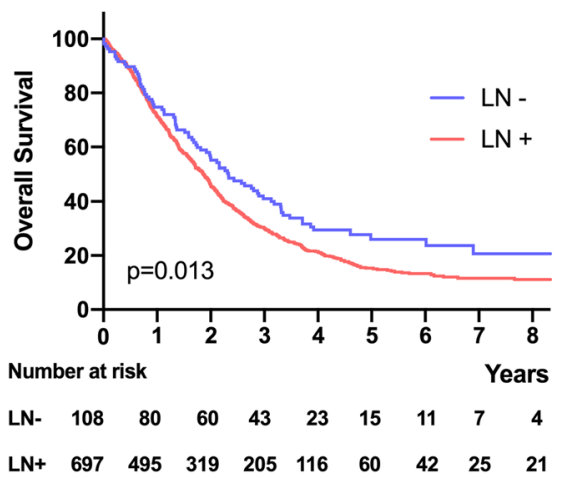

Fig. 2 Survival analysis. a Five-year overall survival rate of all patients ( $L N-v s$. $L N+, p=0.040)$. b Five-year overall survival rate of all patients (RO vs. non-RO, $p=0.013)$. c Five-year overall survival rate of curative (RO) resection patients ( $L N-v s . L N+, p=0.890)$. d 5-year overall survival rate of non-curative (non-R0) resection patients ( $L N-v s . L N+, p=0.013$ ) 
presence of LVI and PNI), thus, resulting in a relatively unfavorable outcome than patients in the $\mathrm{LN}$ - group.

Among the patients, the 5-year OS rate in the $\mathrm{LN}+$ group was significantly lower than that in the LNgroup (LN- vs. $\mathrm{LN}+23.2 \%$ vs. $18.1 \%$; $\mathrm{p}=0.040$ ). The study by Berger et al. suggested that regional LN metastasis is the foremost factor in determining stage II and stage III CRC patients' prognosis [34]. Many studies have also analyzed prognostic factors in mCRC patients and have suggested the negative prognostic impact of regional LN metastasis on OS [7, 8, 23, 24]. The 5-year survival rate in the $\mathrm{R} 0$ resection group was significantly better than that in the non-R0 resection group $(23.4 \%$ vs. $16.7 \%$, respectively; $\mathrm{p}=0.013)$. Nevertheless, the 5year OS rate revealed no significant difference between the $\mathrm{LN}+$ and $\mathrm{LN}$ - groups in $\mathrm{R} 0$ resection patients ( $\mathrm{LN}-$ vs. $\mathrm{LN}+19.5 \%$ vs. $24.3 \% ; \mathrm{p}=0.890)$. This finding may imply that if R0 resection could be achieved, the patients in the LN+ group could have similar favorable survival outcomes as the patients in the LN- group. In other words, mCRC patients with regional LN metastasis may benefit from curative resection of primary and metastatic lesions. In recent retrospective studies, curative resection confers better long-term survival and is an independent factor for predicting better prognosis in patients with mCRC $[35,36]$.

Patients in the LN+ group had a lower rate of lung metastasis but a higher rate of peritoneal seeding and systemic node metastasis than that patients in the LNgroup (lung metastasis in $\mathrm{LN}-$ vs. $\mathrm{LN}+, 25.7 \%$ vs. $14.6 \%$, $\mathrm{p}<0.001$; peritoneal seeding in $\mathrm{LN}-$ vs. $\mathrm{LN}+, 17.4 \%$ vs. $32.4 \%, \mathrm{p}<0.001$; systemic node metastasis in $\mathrm{LN}-\mathrm{vs}$. $\mathrm{LN}+, 6 \%$ vs. $17 \%, \mathrm{p}<0.001)$. These findings may be related to the CRC metastasis routes. The "seed-and-soil" hypotheses of metastatic spread in some studies suggest that metastases in the first draining site may act as seeds for further metastasis. CRC has three metastatic routes, namely, hematogenous, lymphatic, and transcoelomic/ transperitoneal spread. In hematogenous spread, the metastatic sites depend on the location of the primary lesion. Blood is drained from the colon and proximal rectum through the portal system to the liver and then to the lung via the heart, as well as from the middle and distal rectum through the IVC rather than the portal vein, thus directly reaching the lung. Regarding lymphatic spread, all gastrointestinal system sites share a common lymphatic drain flowing through the cisterna chyli to the thoracic duct, then to the left subclavian vein, and finally to the lungs. In transcoelomic/transperitoneal spread, metastases spread through the peritoneal fluid in the peritoneal cavity [24, 27].

We propose two possible mechanisms resulting in more lung metastases in patients with LN- mCRC. First, patients with no regional $\mathrm{LN}$ involvement in malignancy would have higher lung metastasis rates due to cancer cells entering the thoracic duct directly and seeding on the lung parenchyma instead of metastasizing to the regional LNs. Second, cancer cells may have an affinity for organ-specific metastasis. Studies have suggested that CRC metastasis predominantly affects the liver due to a number of factors, including liver circulation patterns and microvessels, metastasis-related genes, chemokines and their receptors, and cellular adhesion molecules [37, 38]. We believe that at least two types of cancer cells are involved: one with more affinity to the liver and the other to the LNs and lungs. If the latter type does not cause metastasis in the LNs, they will cause lung metastasis in the first organ encountered. Adding to this complexity is the fact that LNs have their own blood supply, and thus, lymphatic drains are connected with the blood vessels, suggesting that lymphatic and hematogenous spread might transform one into the other or occur simultaneously.

Systemic LN metastases occur more frequently in patients with $\mathrm{LN}+\mathrm{mCRC}$. This might be because more tumor cells exist in mCRC patients with regional LN metastasis, spreading through the lymphatic system and arresting at systemic LNs. As for the greater frequency of peritoneal metastases in $\mathrm{LN}+\mathrm{mCRC}$ patients, we believe that $\mathrm{mCRC}$ with regional $\mathrm{LN}$ metastasis indicates a more locally advanced disease, which might thus be accompanied by a higher incidence of transperitoneal spread.

This study has some potential limitations. First, this was a retrospective study and, thus, subject to various biases. Second, the cohort only included patients who underwent primary tumor resection with or without distant metastasectomy, which does not represent the entirety of mCRC. Some patients with severe distant metastasis who did not undergo surgical resection of the primary tumor might have had poorer outcomes. Third, the precise metastatic route of distant organs such as the liver and lungs in the LN+ group might be too intricate and complicated to distinguish because hematogenous, lymphatic, and transperitoneal spread, or the combined effect of any two or all three, are equally probable. Fourth, we did not analyze the regimen of postoperative systemic chemotherapy and target therapy in this study, which may have influence on survival. Although we shared similar treatment strategy for mCRC patients treated in this single institute, this may cause bias on OS.

In conclusion, mCRC patients with positive LNs who underwent primary tumor resection may present with high-risk pathological features, including T4 tumors, poorly differentiated adenocarcinoma, LVI, and PNI. Patients with no regional LN involvement in malignancy had a higher rate of lung metastasis, whereas those with 
such involvement had a higher rate of peritoneal seeding and systemic node metastasis. We confirmed that patients with surgically resected positive LNs had much poorer long-term outcomes compared with lymph node negative patients. Nevertheless, with curative resection of both primary and metastatic lesions, mCRC patients with regional lymph node metastasis could have similar survival outcomes as patients without regional lymph node metastasis.

\section{Abbreviations}

mCRC: Metastatic colorectal cancer; CRC: Colorectal cancer; LN: Lymph node; LN-: LN-negative; LN+: LN-positive; OS: Overall survival;

CEA: Carcinoembryonic antigen; LVI: Lymphovascular invasion; PNI: Perineural invasion

\section{Acknowledgements}

This manuscript was edited by Editage Academic Editing.

\section{Authors' contributions}

Concept and design: YTK, JFY. Provision of study patients: WST, HYH, PSH, SFC, CCL, JFY. Collection and assembly of data: YTK. Data analysis and interpretation: YTK, JFY. Manuscript writing: YTK, YJC, YJH, JFY. The authors read and approved the final manuscript.

\section{Funding}

No.

\section{Availability of data and materials}

The datasets used and/or analyzed during the current study are available from the corresponding author on reasonable request.

\section{Declarations}

Ethics approval and consent to participate

This study was approved by the Chang Gung Memorial Hospital Institution Review Board (CGMH IRB 202002199B0).

\section{Consent for publication}

Not applicable.

\section{Competing interests}

The authors declare that they have no competing interests.

\section{Author details}

'Division of Colon and Rectal Surgery, Department of Surgery, Chang Gung Memorial Hospital at Linkou, Chang Gung University College of Medicine, No. 5, Fuxing Street, Guishan District, Taoyuan City, Taiwan. ${ }^{2}$ Division of Colon and Rectal Surgery, Department of Surgery, New Taipei Municipal TuCheng Hospital, Chang Gung Memorial Hospital, New Taipei City, Taiwan.

Received: 23 February 2021 Accepted: 5 May 2021

Published online: 13 May 2021

\section{References}

1. Nitzkorski JR, Farma JM, Watson JC, Siripurapu V, Zhu F, Matteotti RS, et al. Outcome and natural history of patients with stage IV colorectal cancer receiving chemotherapy without primary tumor resection. Ann Surg Oncol. 2012;19(2):379-83. https://doi.org/10.1245/s10434-011-2028-1.

2. Fitzmaurice C, Allen C, Barber RM, et al. Global, regional, and national cancer incidence, mortality, years of life lost, years lived with disability, and disability-adjusted life-years for 32 cancer groups, 1990 to 2015: a systematic analysis for the global burden of disease study. JAMA Oncol. 2017;3:524-48.

3. Adam R, de Gramont A, Figueras J, Kokudo N, Kunstlinger F, Loyer E, et al. Managing synchronous liver metastases from colorectal cancer: a multidisciplinary international consensus. Cancer Treat Rev. 2015;41(9):72941. https://doi.org/10.1016/j.ctrv.2015.06.006.

4. Kopetz S, Chang GJ, Overman MJ, Eng C, Sargent DJ, Larson DW, et al. Improved survival in metastatic colorectal cancer is associated with adoption of hepatic resection and improved chemotherapy. J Clin Oncol. 2009:27(22):3677-83. https://doi.org/10.1200/JCO.2008.20.5278.

5. Van der Pool A, Damhuis R, lizermans J, et al. Trends in incidence, treatment and survival of patients with stage IV colorectal cancer: a population-based series. Colorectal Dis. 2012;14(1):56-61. https://doi.org/10.1111/j.1463-1318.2 010.02539.x

6. 't Lam-Boer J, Van der Geest LG, Verhoef C, Elferink ME, Koopman M, de Wilt $\mathrm{JH}$. Palliative resection of the primary tumor is associated with improved overall survival in incurable stage IV colorectal cancer: a nationwide population-based propensity-score adjusted study in the Netherlands. Int J Cancer 2016;139:2082-2094, 9, doi: https://doi.org/10.1002/ijc.30240.

7. Stillwell AP, Ho YH, Veitch C. Systematic review of prognostic factors related to overall survival in patients with stage IV colorectal cancer and unresectable metastases. World J Surg. 2011;35(3):684-92. https://doi.org/1 0.1007/s00268-010-0891-8.

8. Yun HR, Lee WY, Lee OS, Cho YB, Yun SH, Chun HK. The prognostic factors of stage IV colorectal cancer and assessment of proper treatment according to the patient's status. Int J Colorectal Dis. 2007;22(11):1301-10. https://doi. org/10.1007/s00384-007-0315-x.

9. Venderbosch S, de Wilt JH, Teerenstra S, Loosveld OJ, van Bochove A, Sinnige HA, et al. Prognostic value of resection of primary tumor in patients with stage IV colorectal cancer: retrospective analysis of two randomized studies and a review of the literature. Ann Surg Oncol. 2011;18(12):3252-60. https://doi.org/10.1245/s10434-011-1951-5.

10. Ruo L, Gougoutas C, Paty PB, Guillem JG, Cohen AM, Wong WD. Elective bowel resection for incurable stage IV colorectal cancer: prognostic variables for asymptomatic patients. J Am Coll Surg. 2003;196(5):722-8. https://doi.org/10.1016/S1072-7515(03)00136-4.

11. Verhoef $\mathrm{C}$, de Wilt JH, Burger JW, Verheul HM, Koopman M. Surgery of the primary in stage IV colorectal cancer with unresectable metastases. Eur J Cancer. 2011;47(Suppl 3):S61-6. https://doi.org/10.1016/S0959-8049(11)70148-4.

12. Van Steenbergen $L$, Elferink $M$, Krijnen $P$, et al. Improved survival of colon cancer due to improved treatment and detection: a nationwide populationbased study in the Netherlands 1989-2006. Ann Oncol. 2010;21(11):2206-12. https://doi.org/10.1093/annonc/mdq227.

13. van der Geest $L G$, Koopman $M$, Verhoef $C$, Elferink MA, de Wilt JH. Nationwide trends in incidence, treatment and survival of colorectal cancer patients with synchronous metastases. Clin Exp Metastasis. 2015;32(5):45765. https://doi.org/10.1007/s10585-015-9719-0.

14. Tol J, Koopman M, Cats A, Rodenburg CJ, Creemers GJM, Schrama JG, et al. Chemotherapy, bevacizumab, and cetuximab in metastatic colorectal cancer. N Engl J Med. 2009;360(6):563-72. https://doi.org/10.1056/NEJMoa0808268.

15. Koopman M, Antonini NF, Douma J, Wals J, Honkoop AH, Erdkamp FLG, et al. Sequential versus combination chemotherapy with capecitabine, irinotecan, and oxaliplatin in advanced colorectal cancer (CAIRO): a phase III randomised controlled trial. The Lancet. 2007;370(9582):135-42. https://doi. org/10.1016/50140-6736(07)61086-1.

16. Grothey A, Sargent D, Goldberg RM, Schmoll HJ. Survival of patients with advanced colorectal cancer improves with the availability of fluorouracilleucovorin, irinotecan, and oxaliplatin in the course of treatment. J Clin Oncol. 2004;22(7):1209-14. https://doi.org/10.1200/JCO.2004.11.037.

17. Hurwitz H, Fehrenbacher L, Novotny W, Cartwright T, Hainsworth J, Heim W, et al. Bevacizumab plus irinotecan, fluorouracil, and leucovorin for metastatic colorectal cancer. N Engl J Med. 2004;350(23):2335-42. https:// doi.org/10.1056/NEJMoa032691.

18. Sobrero AF, Maurel J, Fehrenbacher L, Scheithauer W, Abubakr YA, Lutz MP, et al. EPIC: phase III trial of cetuximab plus irinotecan after fluoropyrimidine and oxaliplatin failure in patients with metastatic colorectal cancer. J Clin Oncol. 2008;26(14):2311-9. https://doi.org/10.1200/JCO.2007.13.1193.

19. Mise Y, Zimmitti G, Shindoh J, Kopetz S, Loyer EM, Andreou A, et al. RAS mutations predict radiologic and pathologic response in patients treated with chemotherapy before resection of colorectal liver metastases. Ann Surg Oncol. 2015;22(3):834-42. https://doi.org/10.1245/s10434-014-4042-6.

20. Heinemann V, von Weikersthal LF, Decker T, Kiani A, Vehling-Kaiser U, alBatran SE, et al. FOLFIRI plus cetuximab versus FOLFIRI plus bevacizumab as first-line treatment for patients with metastatic colorectal cancer (FIRE-3): a randomised, open-label, phase 3 trial. Lancet Oncol. 2014;15(10):1065-75. https://doi.org/10.1016/S1470-2045(14)70330-4.

21. Kanas GP, Taylor A, Primrose JN, et al. Survival after liver resection in metastatic colorectal cancer: review and meta-analysis of prognostic factors. Clin Epidemiol. 2012;4:283. 
22. Pfannschmidt J, Dienemann $\mathrm{H}$, Hoffmann $\mathrm{H}$. Surgical resection of pulmonary metastases from colorectal cancer: a systematic review of published series. Ann Thorac Surg. 2007;84(1):324-38. https://doi.org/10.101 6/j.athoracsur.2007.02.093.

23. Ahmed S, Leis A, Chandra-Kanthan S, Fields A, Zaidi A, Abbas T, et al. Regional lymph nodes status and ratio of metastatic to examined lymph nodes correlate with survival in stage IV colorectal cancer. Ann Surg Oncol. 2016;23(7):2287-94. https://doi.org/10.1245/s10434-016-5200-9.

24. Ishihara S, Hayama T, Yamada H, Nozawa K, Matsuda K, Miyata H, et al. Prognostic impact of primary tumor resection and lymph node dissection in stage IV colorectal cancer with unresectable metastasis: a propensity score analysis in a multicenter retrospective study. Ann Surg Oncol. 2014; 21(9):2949-55. https://doi.org/10.1245/s10434-014-3719-1.

25. Enquist IB, Good Z, Jubb AM, et al. Lymph node-independent liver metastasis in a model of metastatic colorectal cancer. Nat Commun. 2014;5: $1-10$.

26. Sadahiro S, Suzuki T, Tanaka A, Okada K, Kamata H. Hematogenous metastatic patterns of curatively resected colon cancer were different from those of stage IV and autopsy cases. Jpn J Clin Oncol. 2013;43(4):444-7. https://doi.org/10.1093/jjco/hyt002.

27. Weiss L, Grundmann E, Torhorst J, Hartveit F, Moberg I, Eder M, et al. Haematogenous metastastic patterns in colonic carcinoma: an analysis of 1541 necropsies. J. Pathol. 1986;150(3):195-203. https://doi.org/10.1002/pa th. 1711500308 .

28. Viadana E, Bross IDJ, Pickren JW. The metastatic spread of cancers of the digestive system in man. Oncology. 1978;35(3):114-26. https://doi.org/10.11 $59 / 000225269$

29. Riihimäki M, Hemminki A, Sundquist J, Hemminki K. Patterns of metastasis in colon and rectal cancer. Sci Rep. 2016;6:1-9.

30. Chang HC, Huang SC, Chen JS, Tang R, Changchien CR, Chiang JM, et al. Risk factors for lymph node metastasis in pT1 and pT2 rectal cancer: a single-institute experience in 943 patients and literature review. Ann Surg Oncol. 2012;19(8):2477-84. https://doi.org/10.1245/s10434-012-2303-9.

31. Huh JW, Lee JH, Kim HR, Kim YJ. Prognostic significance of lymphovascular or perineural invasion in patients with locally advanced colorectal cancer. Am J Surg. 2013;206(5):758-63. https://doi.org/10.1016/j.amjsurg.2013.02.010.

32. Huh JW, Kim HR, Kim YJ. Lymphovascular or perineural invasion may predict lymph node metastasis in patients with $\mathrm{T} 1$ and $\mathrm{T} 2$ colorectal cancer. J Gastrointest Surg. 2010;14(7):1074-80. https://doi.org/10.1007/s11605-010-12 06-y.

33. Liebig C, Ayala G, Wilks J, Verstovsek G, Liu H, Agarwal N, et al. Perineural invasion is an independent predictor of outcome in colorectal cancer. J Clin Oncol. 2009;27(31):5131-7. https://doi.org/10.1200/JCO.2009.22.4949.

34. Berger AC, Sigurdson ER, LeVoyer T, Hanlon A, Mayer RJ, Macdonald JS, et al. Colon cancer survival is associated with decreasing ratio of metastatic to examined lymph nodes. J Clin Oncol. 2005;23(34):8706-12. https://doi. org/10.1200/JCO.2005.02.8852.

35. Sudo M, Furuya S, Shimizu H, et al. Long-term outcomes after surgical resection in patients with stage IV colorectal cancer: a retrospective study of 129 patients at a single institution. World J Surg Oncol. 2019:17:1-8.

36. Miyoshi N, Ohue M, Shingai T, et al. Clinicopathological characteristics and prognosis of stage IV colorectal cancer. Mol Clin Oncol. 2015;3(5):1093-8. https://doi.org/10.3892/mco.2015.598.

37. Jin K, Gao W, Lu Y, Lan H, Teng L, Cao F. Mechanisms regulating colorectal cancer cell metastasis into liver. Oncol Lett. 2012;3(1):11-5. https://doi.org/1 $0.3892 / 01.2011 .432$

38. Le Voyer T, Sigurdson E, Hanlon A, et al. Colon cancer survival is associated with increasing number of lymph nodes analyzed: a secondary survey of intergroup trial INT-0089. J Clin Oncol. 2003;21(15):2912-9. https://doi.org/1 0.1200/JCO.2003.05.062.

\section{Publisher's Note}

Springer Nature remains neutral with regard to jurisdictional claims in published maps and institutional affiliations.

Ready to submit your research? Choose BMC and benefit from:

- fast, convenient online submission

- thorough peer review by experienced researchers in your field

- rapid publication on acceptance

- support for research data, including large and complex data types

- gold Open Access which fosters wider collaboration and increased citations

- maximum visibility for your research: over $100 \mathrm{M}$ website views per year

At BMC, research is always in progress.

Learn more biomedcentral.com/submissions 